\title{
AVULSION OF PERMANENT TEETH: ANALYSIS OF THE EFFICACY OF AN INFORMATIVE CAMPAIGN FOR PROFESSIONALS FROM ELEMENTARY SCHOOLS
}

\author{
Graziela Garrido MORI ${ }^{1}$, Lithiene Ribeiro CASTILHO ${ }^{3}$, Daniele Clapes NUNES ${ }^{3}$, \\ Karina Helga Leal TURCIO ${ }^{1}$, Rodrigo Otoboni MOLINA ${ }^{2}$
}

\author{
1- DDS, MSc, PhD, Professor, Discipline of Integrate Clinics, Dental School of Adamantina, SP, Brazil. \\ 2- DDS, MSc, Professor, Discipline of Integrate Clinics, Dental School of Adamantina, SP, Brazil. \\ 3- DDS, Research Fellow Dental School of Adamantina, Adamantina,SP, Brazil. \\ Corresponding address: Profa. Dra. Graziela Garrido Mori - Rua Oscar de Toledo Cézar, 111 - 19200-000 - Pirapozinho, SP, Brazil
} e-mail: grazielagm@hotmail.com

Received: June 2, 2007 - Accepted: September 28, 2007

\begin{abstract}
$T_{0}$

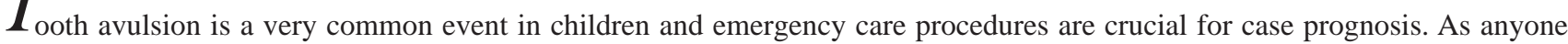
at the moment of accident can provide first-aid measures, knowledge of school professionals dealing with children is of paramount importance. An informative campaign about dental trauma was performed in urban schools in the city of Adamantina, São Paulo state, Brazil, in an attempt to educate school professionals about emergency procedures in cases of tooth avulsion. A questionnaire arguing on personal information, tooth avulsion knowledge and personal impressions of the campaign was handed out for evaluation of the informative campaign. Eighty school professionals participated in the survey. Most participants were females (93.75\%) aged 41-60 years old (53.75\%) with a college degree (77.5\%). Time at work ranged from 1-5 years (22.5\%). The efficacy of the campaign was considered positive, as $100 \%$ of the interviewees replied to the importance of emergency procedures in case of tooth avulsion. In addition, $81.25 \%$ of the respondents answered that they would store the avulsed tooth in some storage medium, of which milk was the most frequently mentioned (84.61\%). The participants considered the campaign as satisfactory and a region-wide campaign will be accomplished at other schools.
\end{abstract}

Uniterms: Delivery of health care; Learning; Tooth injuries.

\section{INTRODUCTION}

Accidents involving the anterior teeth are very common ${ }^{3}$. According to Andreasen and Andreasen ${ }^{3}, 10 \%$ of the population has experienced some kind of dental trauma, of which 0.5 to $16 \%$ were cases of avulsion of permanent teeth.

Once avulsed, the tooth must be replanted into its own socket $^{3}$ in order to reestablish functional normality. For success of replantation, maintenance of viable periodontal ligament cells present on root surface is crucial ${ }^{13,18}$. Hence, immediate replantation ${ }^{2-3,4,15-16}$ (within 15 minutes after avulsion) or storage of the exarticulated tooth in solutions compatible with cell viability until replantation ${ }^{3}$ are critical procedures.

Given that the 7-11-year-old age group is the most commonly affected age range ${ }^{5}$, school professionals should be aware of the importance of immediate treatment procedures in cases of tooth avulsion ${ }^{20}$.

The findings of previous study of our research team ${ }^{20}$ conducted in the city of Adamantina, São Paulo State, Brazil, have shown unawareness of school professionals with respect to emergency procedures for management of avulsed permanent teeth. However, this is not an isolated finding. Other studies have also demonstrated lack of knowledge of school professionals regarding dental trauma ${ }^{1,10-12,24-25}$. Therefore, there is an oncoming need to establish standard operational procedures about initial treatment of tooth avulsion, in order to increase the prognosis of the affected teeth $^{1,10-12,20,24-25}$.

The purpose of this study was to evaluate the efficacy of an informative campaign about how to proceed in cases of dental trauma applied to urban elementary school professionals from the city of Adamantina, Brazil, .

\section{MATERIALAND METHODS}

The informative campaign on tooth avulsion was directed to teachers and employees of elementary schools at the city of Adamantina, São Paulo State, Brazil. These professional 
deal with children in the 7-12-year-old age range.

The campaign was based on use of banners and folders with the heading "Save a tooth", which contained information on what to do in cases of tooth avulsion. The material had simple wording and figures to facilitate understanding by all readers (Figure 1) and was placed on the walls and distributed to teachers and employees of the schools. In addition, school professionals of Adamantina attended seminars on the subject. The didactic material used in the seminars included illustrated slides. Participants were oriented about immediate replantation, appropriate washing of avulsed tooth, with emphasis on extra care not to friction the root surface, storage of the avulsed tooth in milk and referral to the dentist as soon as possible for replantation and follow-up. The participants were encouraged to discuss their doubts and thoughts freely with the presenters.

Twelve of the 19 urban schools existing in Adamantina were visited and had access to folders, posters and lectures. The campaign reached a total of 120 teachers and school staff. In a previous study conducted in schools in Adamantina $^{20}, 117$ teachers and school staff answered a questionnaire for evaluation of their knowledge on tooth avulsion. All participants who had answered the questionnaire before the campaign had access to this information.

Six months after the campaign, the participants were asked to answer to a questionnaire-based survey in order to evaluate the efficacy of the campaign. The questionnaire had to be returned within 7 days with no mention of participant's identity. The survey was divided into 3 parts. Part I consisted of general information, including age, gender, educational level and time at present job. Part II included notions of basic emergency procedures, experience with tooth avulsion, knowledge of handling accidental situations, and knowledge of specific initial procedures in case of tooth avulsion (Figure 2). Part III included questions about the campaign itself (Figure 3).

This questionnaire was based on preexisting models ${ }^{1,10-}$ 12,20. As there is no standard questionnaire validated for such purpose, this questionnaire was adapted and applied for evaluation of the efficacy of the campaign. After the questionnaires had been returned, the answers were counted and the percentages for each question were calculated.

Data obtained in this study were compared to some data of the previous study conducted in Adamantina ${ }^{20}$. The following questions were statistically compared: importance of emergency management of tooth avulsion, storage media employed for avulsed teeth and the most frequently indicated storage medium. Statistical analysis was performed with Epi Info software version 6.04 using the proportion test at 5\% significance level.

\section{RESULTS}

A total of 80 school professionals answered the survey. Most participants were females (93.75\%) between 41-60 years old (53.75\%) with a college degree (77.5\%) and time at work

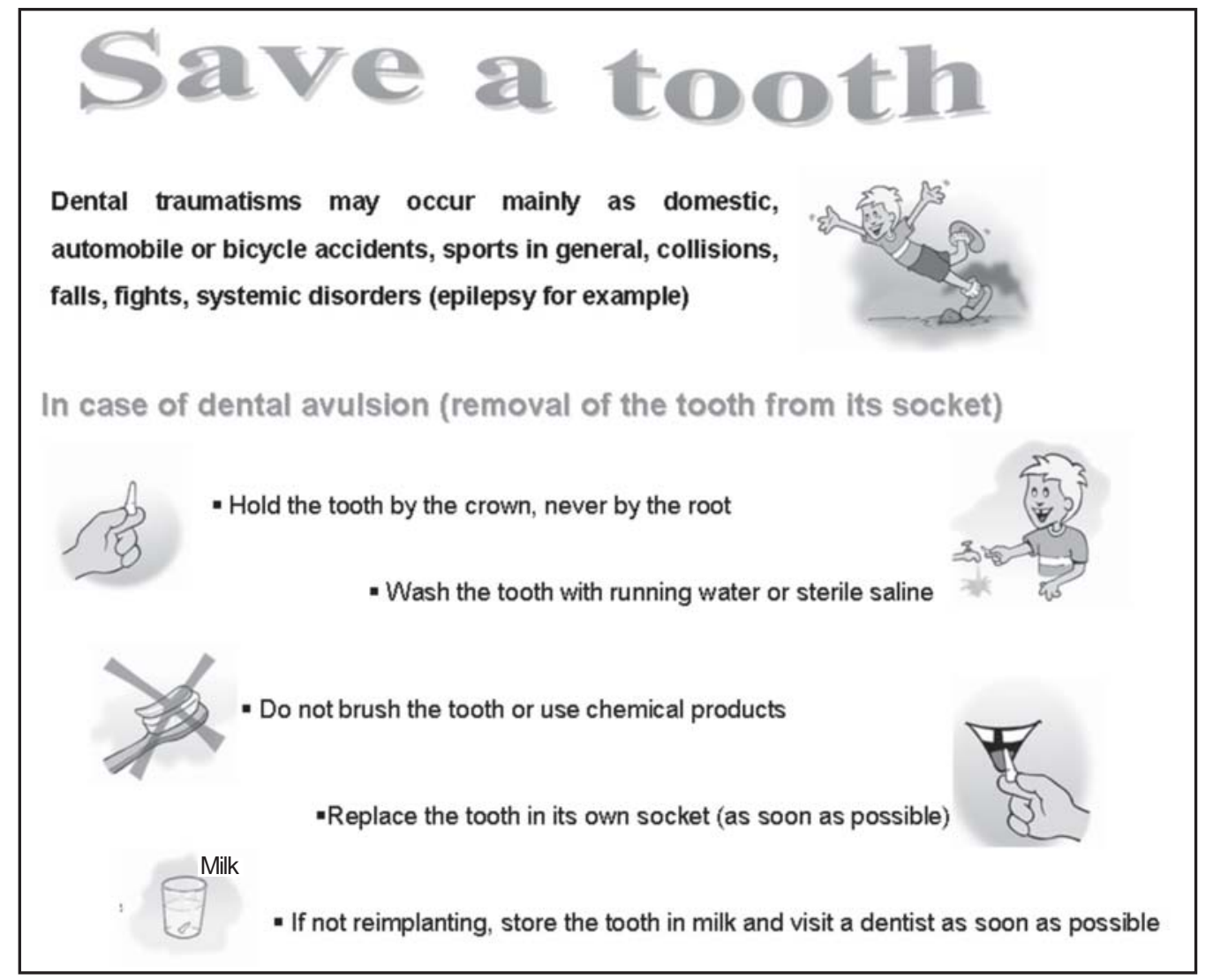

FIGURE 1- Copy of the folder distributed to school professionals in the city of Adamantina, São Paulo State, Brazil, as part of the informative campaign on tooth avulsion 


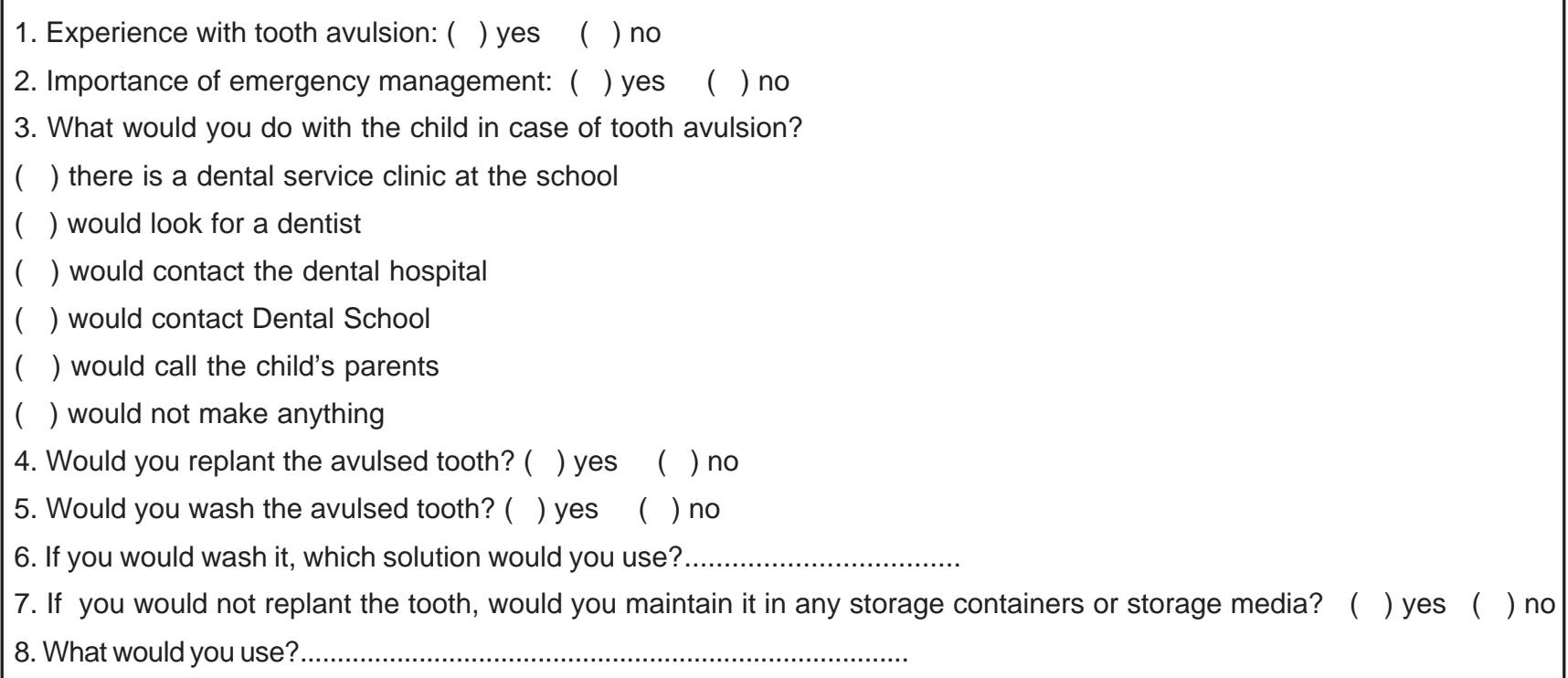

FIGURE 2- Questions in Part II of the questionnaire submitted to the professionals

1. Have you read the posters and folders entitled "Save a tooth" distributed in your school? ( ) yes ( ) no

2. If not, explain why?

3. Have you attended a seminar about dental trauma in your school?

( )yes ( ) no

4. If not, explain why?.

5. Do you think that this campaign has influenced your knowledge about tooth avulsion? ( ) yes ( ) no

6. Please give your opinion about the seminars, folders and posters used in the

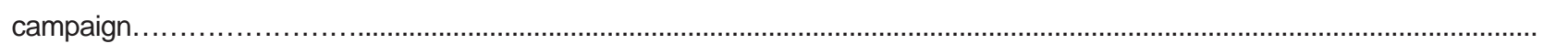

FIGURE 3- Questions in Part III of the questionnaire submitted to the professionals

ranging from $1-5$ years (22.5\%).

When asked if they had experience with dental traumatisms, only $13.75 \%$ answered yes, and $100 \%$ of the participants considered emergency procedures to be mandatory in such cases. In case of a student getting hurt, 42.5\% said they would seek help from the school dentist, $31.25 \%$ would seek a dentist in town and $15 \%$ would call the student's parents. Only 6.25\% said they would seek treatment at dental schools and 3.75\% would seek the local health system.

The questions regarding tooth avulsion revealed that only $2.5 \%$ of school professionals would replant an avulsed tooth. Of the 80 participants, $42.5 \%$ would wash the avulsed tooth; of these, $44 \%$ would use milk and $38.6 \%$ would use water.

For $81.25 \%$ of the participants, the avulsed tooth should be kept in a storage medium if replantation could not be performed immediately. Moreover, of this total, $84.61 \%$ would place the tooth in milk, 3.06\% in water, 1.53\% in saliva and $7.66 \%$ would keep the tooth involved in paper or plastic (dry) (Figure 4).

The answers to Part III of the survey demonstrated that

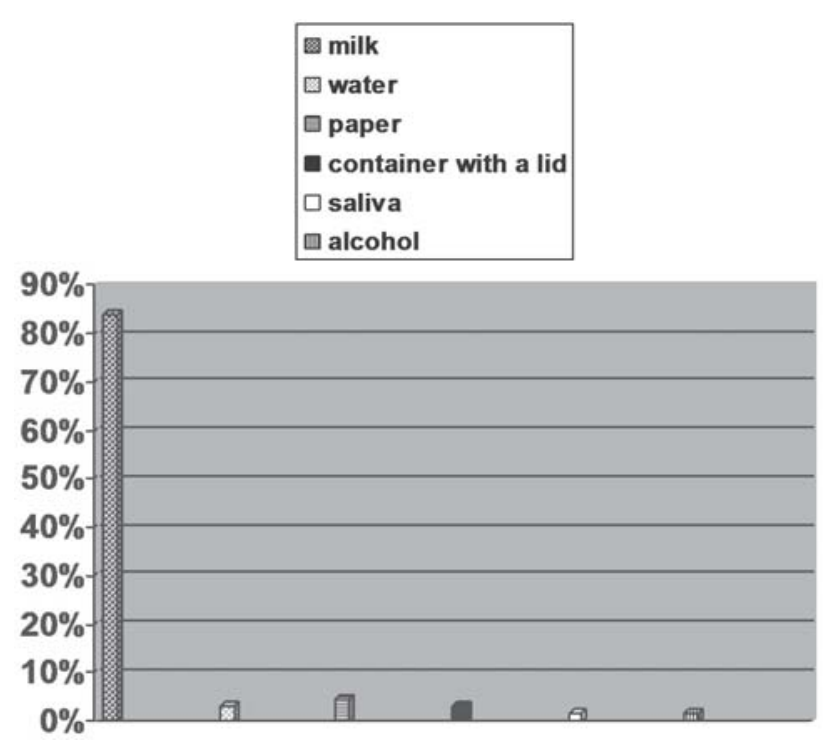

FIGURE 4- Storage solutions to be used by school professionals in the city of Adamantina, São Paulo State, Brazil, in case of tooth avulsion 


\begin{tabular}{|c|c|c|}
\hline Questions & $\begin{array}{l}\text { Answers obtained before the } \\
\text { campaign }^{23}\end{array}$ & $\begin{array}{l}\text { Answers obtained after the } \\
\text { campaign }\end{array}$ \\
\hline $\begin{array}{c}\text { Importance of emergency } \\
\text { management }\end{array}$ & $75.2 \%$ answered yes ${ }^{a}$ & $100 \%$ answered yes ${ }^{b}$ \\
\hline $\begin{array}{l}\text { Would you maintain the tooth in } \\
\text { any storage containers or storage } \\
\text { media? }\end{array}$ & $77.3 \%$ answered yes ${ }^{a}$ & $92.34 \%$ answered yes ${ }^{b}$ \\
\hline $\begin{array}{l}\text { Which storage medium would you } \\
\text { use? }\end{array}$ & $\begin{array}{l}\text { 7.6\% answered that they would use } \\
\text { milk }^{\mathrm{a}}\end{array}$ & $\begin{array}{l}84.61 \% \text { answered that they would } \\
\text { use milk }\end{array}$ \\
\hline
\end{tabular}

Different letters indicate statistically significant difference at $5 \%$.

FIGURE 5- Comparison of data obtained before and after the informative campaign on tooth avulsion

the campaign was well-accepted by the participants. Only $11.25 \%$ reported not to have read the informative posters and $3.25 \%$ had not attended the seminars. Professionals who did not know about the campaign either missed work on a seminar day or did not receive the folders. Participants of the seminars $(96.25 \%)$ and readers of the posters and folders $(88.75 \%)$ considered the campaign as a positive and clarifying resource and approved the accomplishment of similar campaigns in other schools.

Comparison of data to those of the previous study conducted in Adamantina ${ }^{20}$ pointed to the efficacy of the campaign. The statistical analysis revealed statistically significant difference between data, as presented in Figure 5.

\section{DISCUSSION}

It is known that when replantation is performed immediately after tooth avulsion (up to 15 minutes) ${ }^{2-3,5,16}$ or when the tooth is stored in appropriate solutions compatible with cell survival ${ }^{6-9,14-15,17,19,21-23,26-27}$, case prognosis is greatly enhanced. When immediate replantation is impossible, storage of the tooth in a humid environment is mandatory ${ }^{3}$. Milk has been indicated as the preferred storage medium for avulsed teeth in several countries. In addition to being readily available, it preserves cell viability for up to 6 hours $^{9,22}$. Keeping the tooth dry compromises the periodontal ligament cells and the prognosis is poor ${ }^{3}$.

Children between 7 and 11 years of age are the most commonly affected by dental trauma ${ }^{5}$. Therefore, professionals that work with children must be aware of the importance of emergency treatment and how to proceed in cases of tooth avulsion.

Other studies have demonstrated unawareness of school professionals regarding handling of dental traumatisms ${ }^{1,10-}$ 12,20,24-25. Mori et al. ${ }^{20}$ conducted a study in Adamantina six months before the campaign and observed that only $7.6 \%$ of school professionals would place the tooth in milk for transportation to the dental office. Unfortunately, these data contribute to the failure of tooth replantation.

In addition to the lack of knowledge, other investigators ${ }^{1,10-12,20,24-25}$ have also reported the importance of a massive awareness of the population about dental trauma, usually by means of informative campaigns. Nonetheless, the spread of information about emergency procedures in cases of dental trauma is often needed.

In the present study, a campaign for providing information about dental trauma to school professionals was performed in Adamantina, São Paulo State, Brazil. The purpose of the campaign was to alert school professionals on the importance of immediate treatment procedures in case of tooth avulsion and instruct them on how to handle these situations.

The results of the survey, applied 6 months after the campaign, revealed that the professionals realized how crucial immediate treatment is for cases of tooth avulsion, as $100 \%$ of the participants answered positively to this question. We noted that after the campaign, a larger number of professionals (92.34\%) said they would store the avulsed tooth in some storage medium; milk was the preferred solution (84.61\%). In a previous study conducted with the same population, only $42 \%$ would place the tooth in some kind of liquid, and milk would be used in only $7.6 \%$ of the cases $^{20}$. The results of that study ${ }^{20}$ could be compared to the data collected after completion of the campaign, confirming its efficacy (Figure 3).

The results were positive after the campaign due to the promotion of awareness of school professionals. The informative folders, posters and lectures achieved their goal, namely to widen the knowledge of these professionals on tooth avulsion. Thus, the use of information in a clear and simple manner is one of the best ways to improve treatment success of avulsed permanent teeth. 


\section{CONCLUSION}

These results confirm the efficacy of the campaign, which was considered approved by all participants. This suggests that accomplishment of informative campaigns about tooth avulsion in schools is a valid alternative and can be extended to the general population to further increase success rates of treatment of tooth avulsion and consequently promote oral health.

\section{REFERENCES}

1- Al-Jundi SH, Al-Waeili H, Khairalah K. Knowledge and attitude of Jordanian school health teachers with regards to emergency management of dental trauma. Dent Traumatol. 2005;21(4):183-7.

2- Andersson L, Bodin I. Avulsed human teeth replanted within 15 minutes: a long-term clinical follow-up study. Endod Dent Traumatol. 1990;6(1):37-42.

3- Andreasen JO, Andreasen FM. Textbook and colour atlas of traumatic injuries to the teeth, $3^{\text {rd }}$ edn. Copenhagen: Munksgaard Publishers; 1994.

4- Andreasen JO. Analysis of pathogenesis and topography of replacement root resorption (ankylosis) after replantation of mature permanent incisors in monkeys. Sweed Dent J. 1980;4(6):231-40.

5- Andreasen JO. Etiology and pathogenesis of traumatic dental injuries. A clinical study of 1298 cases. Scand J Dent Res. 1970;78(4):329-42.

6- Ashkenazi M, Marouni M, Sarnat H. In vitro viability, mitogenicity and clonogenic capacities of periodontal ligament fibroblasts after storage in four media supplemented with growth factors. Dent Traumatol. 2001;17:27-35.

7- Blomlöf L, Andersson L, Lindskog S, Hedstrom KG, Hammarstrom L. Periodontal healing of replanted monkey teeth prevented from drying. Acta Odont Scand. 1983;41(2):117-23.

8- Blomlöf L, Otteskog P, Hammarström L. Effect of storage in media with different ion strengths and osmolalities on human periodontal ligament cells. Scand J Dent Res. 1981;89(2):180-7.

9- Blomlöf L, Lindskog S, Andersson L, Hedstrom KG, Hammarstrom L. Storage of experimentally avulsed teeth in milk prior to replantation. J Dent Res. 1983;62(8):912-6.

10- Caglar E, Ferreira LP, Kargul B. Dental trauma management knowledge among a group of teachers in two south European cities. Dent Traumatol. 2005;21(5):258-62.

11- Chan AWK, Wong TKS, Cheung GSP. Lay knowledge of physical education teachers about the emergency management of dental trauma in Hong Kong. Dent Traumatol 2001;17:77-85.

12- Hamilton FA, Hill FJ Mackie IC. Investigation of lay knowledge of management of avulsed permanent incisors. Endod Dent Traumatol. 1997;13(1):19-23.

13- Hammarström L, Blomlöf L, Lindskog S. Dynamics of dentoalveolar ankylosis and associated root resorption. Endod Dent Traumatol. 1989;5(4):163-75.

14- Hiltz J, Trope M. Vitality of human lip fibroblasts in milk, Hanks balanced salt solution and Viaspan storage media. Endod Dent Traumatol. 1991;7(2):69-77.
15- Kenny DJ, Barrett EJ. Pre-replantation storage of avulsed teeth: fact and fiction. CDA J. 2001;29(4):275-81.

16- Layung ML, Barrett EJ, Kenny DJ. Interium storage of avulsed permanent teeth. J Can Dent Assoc. 1998;64(5):357-69.

17- Lindskog S, Bomlöf L, Hammarström L. Mitoses and microorganisms in the periodontal membrane after storage in milk or saliva. Scand J Dent Res. 1981;91:465-72.

18- Löe H, Waerhaug J. Experimental replantation of teeth in dogs and monkeys. Arch oral Biol. 1961; 3(3):176-84.

19- Marino TG, West LA, Liewehr FR, Mailhot JM, Buxton TB, Runner RR, et al. Determination of periodontal ligament cell viability in long shelf-life milk. J Endod. 2000;26(1):699-702.

20- Mori GG, Turcio KHL, Borro VP, Mariusso AM. Evaluation of the knowledge on tooth avulsion of school professionals from Adamantina, São Paulo, Brazil. Dent Traumatol. 2007;23(1):2-5.

21- Oswald RJ, Harrington GW, Van Hassel HJ. A postreplantation evaluation of air-dried and saliva stored avulsed teeth. J Endod. 1980;6(5):546-51.

22- Pearson RM, Liewehr FR, West LA, Patton WR, McPherson JC 3rd, Runner RR. Human periodontal ligament cell viability in milk and milk substitutes. J Endod. 2003;29(3):184-6.

23- Pierce AM. Experimental basis for the management of dental resorption. Endod Dent Traumatol. 1989;5(6):255-65.

24- Raphael LS, Gregory PJ. Parental awareness of the emergency management of avulsed teeth in children. Aust Dent J. 1990;35(2):1303.

25- Sae-Lim V, Lim LP. Dental trauma management awareness of Singapore pré-school teachers. Dent Traumatol. 2001;17:71-6

26- Trope M, Yesilsoy C, Koren L, Moshonov J, Friedman S. Effect of different endodontic treatment protocols on periodontal repair and root resorption of replanted dog teeth. J Endod 1992; 18(10): 492-6.

27- Trope M, Friedman S. Periodontal healing of replanted dog teeth stored in Viaspan, milk and Hank's balanced salt solution. Endod Dent Traumatol. 1992;8:183-8 